\title{
Monitoring Level Air Pada Waduk Secara Realtime Berbasis IoT Memanfaatkan Aplikasi Telegram
}

\author{
Muhammad Kresna $^{1}$, Kunto Eko Susilo ${ }^{2}$ \\ Program Studi Sistem Komputer, Universitas Narotama \\ Jl. Arief Rachman Hakim 51, Surabaya, Indonesia \\ 1,muhammad.kresna@mhs.fasilkom.narotama.ac.id \\ ${ }^{2}$ kunto.eko.susilo@narotama.ac.id
}

Diterima : 31 Agustus 2021

Disetujui : 28 September 2021

\begin{abstract}
Abstrak-Manfaat dari dibangunnya waduk beragam seperti reservoir air untuk irigasi, air baku, pembangkit listrik, sebagai tangkapan air untuk pengendalian banjir, dan tempat wisata disaat yang bersamaan. Tetapi, cuaca yang berubah-ubah menyebabkan volume air dapat meluap sewaktuwaktu jika tidak dipantau dengan baik. Penelitian ini dilakukan untuk merancang Sebuah alat monitoring level air pada waduk melalui Telegram. Alat ini dirancang menggunakan ESP8266 sebagai komputer mini untuk mengatur kerja sistem, Sensor ultrasonik $\quad$ HC-SR04 sebagai pembaca level air, motor servo sebagai alat buka tutup kran otomatis, buzzer sebagai sinyal peringatan, dan aplikasi messengger Telegram yang telah diunduh dan dipasang pada smartphone. Hasilnya menunjukkan bahwa alat tersebut dapat memberikan informasi tingkat air di waduk. Pengguna juga bisa meminta informasi level air pada waduk, dimana alat memberikan informasi secara otomatis ketika air waduk melebihi ambang batas normal.
\end{abstract}

Keywords—ESP8266, Telegram, Waduk, sensor ultrasonik, IoT

\section{PENDAHULUAN}

Waduk adalah wadah buatan terbentuk secara alami maupun buatan sebagai akibat dibangunnya bendungan yang memiliki fungsi selain untuk menahan dan menampung air, juga digunakan untuk menampung limbah ataupun menampung lumpur. Manfaat dari dibangunnya waduk juga beragam seperti Reservoir air untuk irigasi, air baku, pembangkit listrik, tangkapan air untuk pengendalian banjir, dan tempat wisata disaat yang bersamaan.

Tetapi, cuaca yang berubah-ubah menyebabkan volume air tidak menentu. Volume air Waduk pada saat musim hujan dapat

menyebabkan air meluap di sungai dan mengakibatkan banjir. Sedangkan saat kemarau volume air waduk mengalami penurunan sehingga tidak mampu memenuhi kebutuhan air.

Kondisi volume air waduk ini merupakan informasi yang penting untuk masyarakat di sekitar Waduk. Informasi kondisi air di waduk bisa digunakan untuk berjaga-jaga apabila tiba air waduk meluap ataupun mengalami penurunan.

Keinginan untuk membuat monitoring ketinggian air waduk pun mulai berkembang, baik yang memakai SMS Gateway, Sensor, WEB Server, maupun Smartphone, baik yang berupa Aplikasi langsung ataupun menggunakan Aplikasi Messenger, dan masih banyak lagi. Seperti pada penelitian yang ditulis oleh (Zuly Budiarso, 2011), tentang Sistem Monitoring Tingkat Ketinggian Air Bendungan Bebasis Mikrokontroller ini digunakan mikrokontroller ATMega 8535, dan LCD Display untuk memantau ketinggian air.

Dalam perancangan perangkat keras diperlukan ketelitian dalam menghitung besar kecilnya ltegangan dan arus yang dihasilkan oleh sensor, sensor akan berpengaruh pada kinerja mikrokont roler [1]. Sedangkan pada tahun 2013, penelitian 
dilakukan oleh Irma menghasilkan sistem deteksi ketinggian air menggunakan Mikrokontroller AT89S51. Sistem ini menggunakan sensor konduktifitas untuk mendeteksi ketinggian air pada bendungan. Data kemudian dikirim ke Aplikasi pada Telepon seluler Android menggunakan Jaringan Wifi [3].

Pada penelitian ini penulis menggunakan Mikrokontroller ESP8266 dan Aplikasi Messenger sebab mempunyai unsur praktis dan Aplikasi Messenger sering kita gunakan dalam aktifitas harian di Smartphone kita, contohnya: Line, Telegram, Whatsapp, dll. Oleh karena itu, penulis mengangkat judul "Monitoring Level Air Pada Waduk Secara Real Time Berbasis IoT Memanfaatkan Aplikasi Telegram" yang diharapkan dapat membantu sistem pengontrolan dan monitoring level air pada waduk dan dapat diterapkan di konsep IoT untuk mengontrol dan memonitoring alat elektronik lainnya.

\section{TINJAUAN PUSTAKA}

\section{A. Penelitian Terkait}

Penelitian ini dilakukan tidak terlepas dari hasil penelitian-penelitian terdahulu yang pernah dilaksanakan sebelumnya :

Penelitian Pertama : Penelitian berjudul Sistem Monitoring Tingkat Ketinggian Air Bend ungan Bebasis Mikrokontroller yang ditulis oleh Ir. Zuly Budiarso, M.Cs, Eddy Nurraharjo, S.T., M.Cs. Hasil yang diperoleh dalam penelitian ini adalah dalam perancangan perangkat keras diperlukan ketelitian dalam menghitung besar kecilnya tegangan dan arus yang dihasilkan oleh sensor, karena besarnya tegangan yang dihasilka n oleh sensor akan berpengaruh pada kinerja mik rokontroler. Hasil yang diperoleh dari peralatan ini masih bersifat kualitatif. Agar peralatan dapat berfungsi secara optimal diperlukan sensor yang dapat mengasilkan besaran sinyal secara kuantitatif. Sehingga perubahan tingkat ketinggia n dapat diamati lebih teliti [1].

Penelitian Kedua : Penelitian berjudul Sistem Monitoring dan Peringatan Ketinggian Ai $r$ berbasis Web dan SMS Gateway yang ditulis oleh Alfred Tenggono, Yovan Wijaya, Erick Kusuma, Welly. Dengan menggunakan metode waterfall dibuat sebuah sistem monitoring dan peringatan yang menggunakan web dan sms gateway[2].Sistem monitoring ketinggian air

dibuat agar dapat mudah diakses kapan saja dan dimana saja. Sistem peringatan juga dibuat agar dapat menyampaikan peringatan dengan cepat, dan memiliki wilayah cakupan yang luas[2].

Dengan menggunakan sistem ini dapat dipantau ketinggian air secara real time melalui halaman web, dan mendapatkan peringatan akan terjadinya banjir melalui pesan singkat. Sehingga sistem ini dapat membantu pengguna, terhindar ataupun dapat menekan kerugian yang ditimbulkan dari banjir yang terjadi [2].

Penelitian ketiga : Penelitian berjudul Perancangan Monitoring Jarak Jauh Ketinggian Air pada Bendungan Menggunakan Sistem Android Via Jaringan Wi-fi yang ditulis oleh Irma Sika Girsang, Dr. Bisman Perangin-angin, M.Eng. Sc. Dari hasil pengujian alat ini, bahwa sensor konduktifitas mendeteksi ketinggian air pada bendungan dan dapat dimonitoring bendungan tersebut dari jarak jauh dengan menggunakan sistem android via jaringan wi-fi, bahwa mikrokontroler AT89S51 sebagai pengontrol dapat dikendalikan dengan menggunakan program Codevision AVR yang juga dihubungkan pada PC sehingga dapat ditampilkan visualisasi bendungan dengan program Visual basic 6.0 dan dimonitoring dari jarak jauh menggunakan sistem android Via jaringan wi-fi, dan alat ini mampu memonitoring ketinggian air pada bendungan dari jarak jauh menggunakan sistem android via jaringan wi-fi [3].

Dari ketiga penelitian diatas penggunaan mikrokontroller masih harus terhubung ke PC sehingga kurang efisien terlebih jika perangkat mati, maka source code harus di compile lagi ke mikrokontroller agar bisa berfungsi kembali. Dan juga penggunaan sistem notifikasi menggunakan SMS Gateway juga sudah mulai berkurang karena berkembangnya smartphone. Oleh karena itu penulis mengunakan Mikrokontroller ESP8266 agar source code dapat tersimpan dalam ROM, sehingga ESP8266 tidak harus selalu terhubung ke PC, dan menggunakan Aplikasi Messenger Telegram karena memiliki unsur praktis dan juga sering kita gunakan dalam aktifitas sehari-hari di Smartphone kita.

B. IoT

Internet of Things (IoT) adalah sebuah konsep di mana suatu objek yang memiliki kemampuan untuk mentransfer data melalui jaringan tanpa memerlukan adanya interaksi dari manusia ke manusia atau dari manusia ke kompu ter[12]. Internet of Things (IoT) 
adalah struktur di mana objek, orang disediakan dengan identitas eksklusif dan kemampuan untuk pindah data melalui jaringan tanpa memerlukan dua arah antara manusia ke manusia yaitu sumbe $r$ ke tujuan atau interaksi manusia ke komputer [12].

IoT telah berkembang cukup pesat mulai dari gabungan teknologi nirkabel, Micro Electromechanical Systems (MEMS) dan juga Internet[13]. IoT memakai teknologiyang secara garis besar digabung menjadi suatu kesatuan diantaranya sensor sebagai pembaca data, koneksi internet dengan bebarapa macam topologi jaringan, Radio Frequency Identi fication (RFID), wireless sensor network dan teknologi yang terus akan bertambah sesuai dengan kebutuhan [13].

\section{ESP8266}

ESP8266 adalah microchip Wi-Fi murah, dengan TCP / IP dan kemampuan mikrokontroler, diproduksi oleh Espressif Systems di Shanghai, Cina. Modul ESP8266 sudah tidak memerlukan mikrokontroller tambahan lagi karena di dalamnya sudah ada SoC (System on Chip) sehingga tinggal kita progam saja.

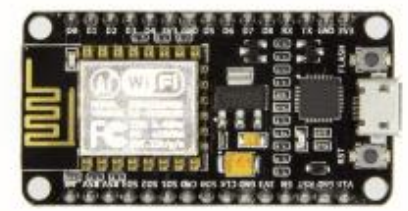

Gambar 1. ESP8266 [14].

\section{Sensor Ultrasonik}

Sensor adalah alat yang digunakan untuk merubah suatu besaran fisik menjadi besaran listrik sehingga dapat dianalisa dengan rangkaian listrik tertentu.

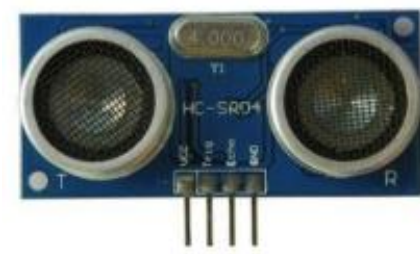

Gambar 2. Sensor Ultrasonik HC-SR04 [6].

Sensor ultrasonik merupakan sensor yang menggunakan prinsip pantulan gelombang suara, digunakan untuk mendeteksi keberadaan suatu objek $[5,6,7]$. Sensor ultrasonik tipe HCSR04 merupakan perangkat yang digunakan untuk mengukur jarak dari suatu objek[6]. Jarak yang bisa diukur sekitar 2-450 $\mathrm{cm}$. Alat ini menggunakan dua pin digital untuk mengkomunikasikan jarak yang

terbaca. Prinsip kerja sensor ultrasonik ini bekerj a dengan mengirimkan pulsa ultrasonik sekitar $40 \mathrm{KHz}$, kemudian dapat memantulkan pulsa echo kembali, dan menghitung waktu yang diambil dalam mikrodetik. Kita dapat memicu pulsa secepat 20 kali per detik dan itu bisa tentukan objek hingga 3 meter [7].

\section{E. Motor Servo}

Motor servo merupakan jenis

motoryang digunakan sebagai penggerak pada sistem servo (servosystem) seperti pada penggerak pada kontrol posisi lengan robot.Motor servo secara struktur mesin 2 macam: de servo motor dan ac servo motor. F. Telegram

Telegram merupakan sebuah aplikasi yang dibuat oleh Telegram Messenger LLP dan didukuung oleh Wirausahawan Rusia

Pavel Durov. Telegram adalah sebuah aplikasi layanan pengirim pesan instan multiplatform berbasis awan yang bersifat gratis dimana para pengguna dapat mengirim pesan dan bertukar foto, video, stiker, audio, dan tipe berkas lainnya [4].

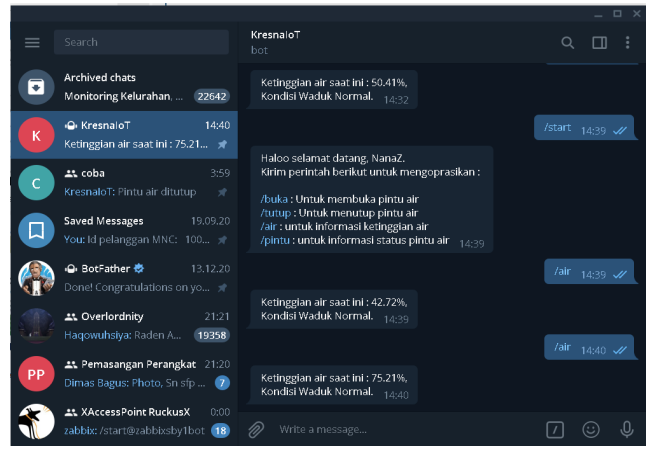

Gambar 3. Telegram versi Dekstop.

\section{Metode PENELITIAN}

Dalam bab ini berisi pembahasan tentang tahap-tahap dalam penelitian yang dilakukan oleh penulis. 


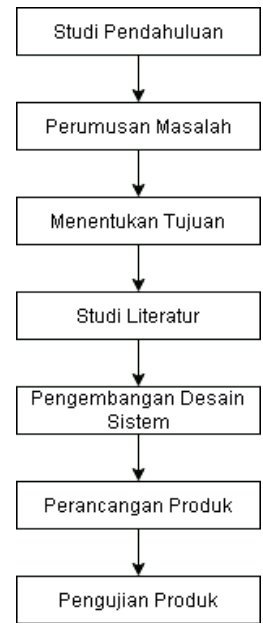

Gambar 4. Tahap Penelitian.

Berikut adalah penjelasan dari tahaptahap penelitan yang ada pada gambar diatas.

1. Studi Pendahuluan

Merupakan tahap awal dalam penelitian yang bertujuan untuk mengidentifikasi masalah yang berkaitan dengan topik penelitian, sehingga peneliti mengetahui masalah yang harus dipecahkan.

2. Perumusan Masalah

Perumusan masalah ini bertujuan agar peneliti memahami permasalahan secara spesifik sehingga dapat lebih mudah dan fokus dalam menyelesaikan masalah tersebut melalui penelitian.

3. Menentukan Tujuan

Pada tahap ini peneliti menentukan tujuan penelitian yaitu menciptakan sebuah monitoring ketinggian air yang bisa dioperasikan secara wireless melalui Wi-Fi menggantikan fungsi dari penjagaan secara manual untuk mengecek ketinggian air pada waduk secara realtime.

4. Studi Literatur

Peneliti melakukan studi literatur dengan mengumpulkan, membaca, dan memahami referensi yang berasal dari jurnal penelitian, buku elektronik (ebook), datasheet komponen, dan sumber pustaka lainnya yang berkaitan dengan topik penelitian antara lain yaitu IoT, ESP8266, Telegram.

5. Pengembangan Desain Sistem

Pada tahap ini peneliti melakukan perancangan desai sistem atau model dari alat yang akan dibuat. Desain sistem sendiri terdiri dari diagram blok sistem dan gambaran sistem secara keseluruhan
6. Perancangan Produk

Tahap ini terdiri dari perancanga

7. perangkat keras dan perancangan perangkat lunak. Perancangan perangkat keras terdiri dari perancangan mekanik dan perancangan elektrik. Perancangan perangkat lunak terdiri dari pembuatan $B$ ot pada Telegram, dan perancangan program pada ESP8266.

an Produk

Pada tahap ini peneliti melakukan pengujian pada produk untuk mengetahui tingkat keberhasilan alat yang telah dibuat. Terdapat dua macam pengujian yaitu pengujian hardware dan pengujian software.

\section{A. Blok Diagram Sistem}

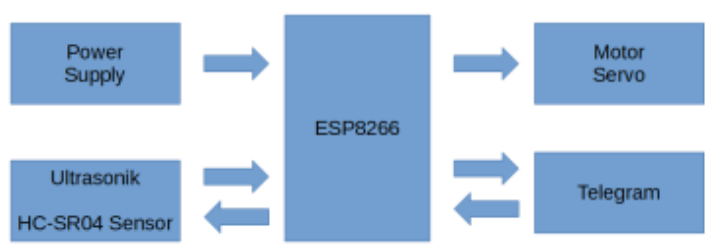

Gambar 5. Blok Diagram Sistem.

Penjelasan blok diagram sistem diatas, sebagai berikut :

a) Power Supply : Berfungsi sebagai daya listrik pada sistem.

b) Motor Servo : Berfungsi sebagai penggerak kran otomatis.

c) Sensor Ultrasonik : Berfungsi sebagai sensor pendeteksi ketinggian air.

d) ESP8266 : Berfungsi sebagai pemroses data input dan output data melalui pengiriman data lewat modul Wi-Fi.

e) Aplikasi Telegram : Berfungsi sebagai User Interface untuk menampilkan output data dan juga sebagai input perintah.

\section{B. Perancangan Alat}

i. Perancangan Mekanik

Pada penelitian kali ini, peneliti menggunakan bak air sebagai miniatur waduk kemudian pada satu sisi dipasangkan sensor ultrasonik sebagai pendeteksi ketinggian air, dan pada sisi lainnya diberikan lubang untuk tempat kran air yang akan difungsikan sebagai pintu air otomatis. 


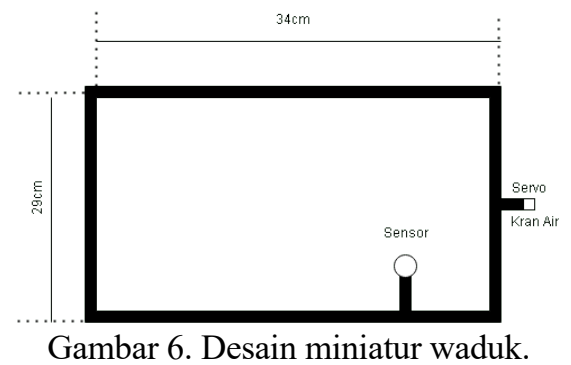

ii. Perancangan Mekanik

Alat pada penelitian ini diatur oleh sebuah ESP8266 dan Sensor Ultrasonik. Untuk lebih jelasnya lihat Gambar 3.4.

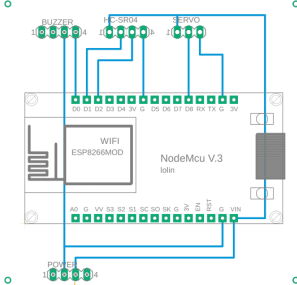

Gambar 7. Skematik Rangkaian Sistem.

Monitoring Level Air

\section{Perancangan Perangkat Lunak}

Perancangan perangkat lunak menunjukkan bagaimana sistem kerja alat yang sudah dibuat.

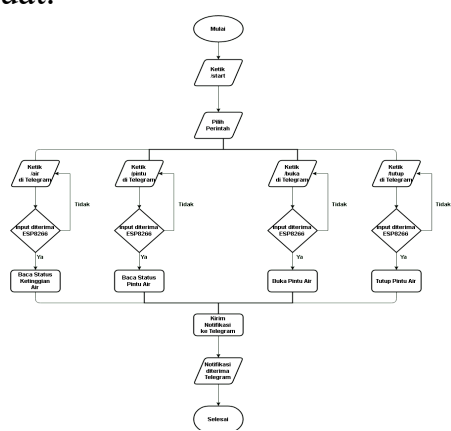

Gambar 8. Flowchart dari Bot Telegram.

Alur program pada penelitian ini adalah memulai program dengan mengetikkan perintah "start" pada chat bot telegram. Selanjuatnya akan muncul balasan selamat datang dari ESP8266 beserta petunjuk penggunaan untuk melihat kondisi ketinggian air pada waduk. Tidak hanya dapat membaca ketinggian air, kita juga bisa mengetikkan perintah "/pintu" untuk mengetahui status pintu air saat ini masih tertutup atau terbuka. Untuk membuka ataupun menutup pintu air bisa dilakukan dengan 2 cara, pertama secara manual dengan mengetikkan perintah "/buka" atau "/tutup", dan yang kedua secara otomatis sesuai ketinggian air. Untuk lebih jelasnya perhatikan gambar 8 .

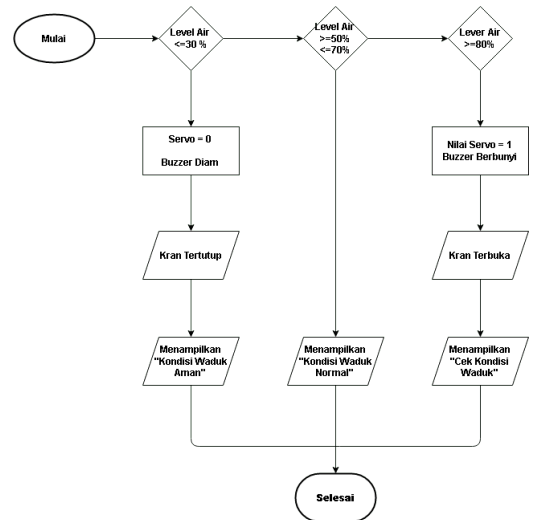

Gambar 9. Subprogram Pengiriman Informasi.

Seperti terlihat pada Gambar 8, saat ketinggian air mencapai lebih kecil sama dengan $30 \%$ maka servo akan bernilai 0 dan buzzer diam, sehingga pintu akan tertutup kemudian menampilkan pesan notifikasi di Telegram bahwa "Ketinggian Air saat ini (dalam\%). Kondisi Waduk Aman". Saat ketinggian air mencapai lebih besar sama dengan $80 \%$ maka servo akan bernilai 1 dan buzzer akan berbunyi, menandakan pintu air terbuka secara otomatis dan akan muncul pesan notifikasi di Telegram "Ketinggian Air saat ini (dalam\%). Cek Kondisi Waduk". Sedangkan saat ketinggian air berada pada $50 \%$ sampai $60 \%$ servo akan mengikuti kondisi terakhir apakah dia bernilai 0 atau 1 dan menampilkan pesan "Ketinggian Air saat ini (dalam\%). Kondisi Waduk Normal".

D. Pembuatan Bot Telegram

Pertama untuk membuat bot pada Telegram cari BotFather pada kolom pencarian di Telegram. Bot Father merupakan sebuah bot yang berfugsi untuk membuat dan mengatur bot yang akan kita buat. Bot Father memiliki banyak fungsi, misalnya membuat bot, mengubah nama bot, mengatur deskripsi bot,dll.

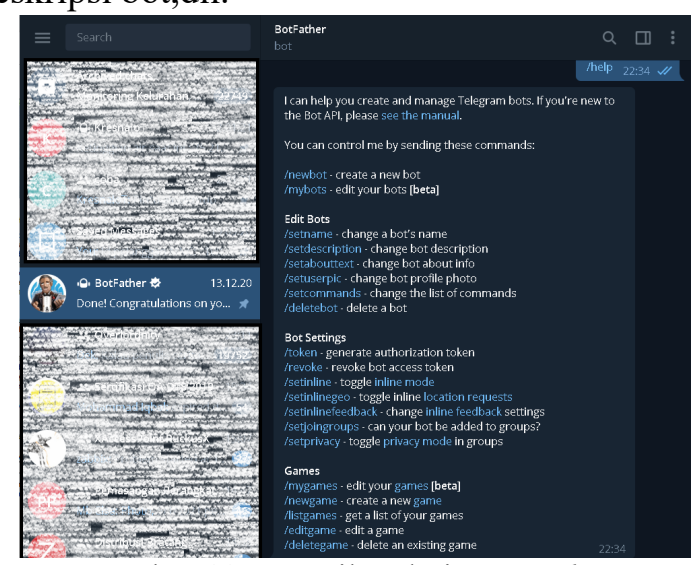

Gambar 10. Tampilan dari Bot Father.

Untuk membuat buat bot baru ketik perintah "/newbot", kemudian kita diminta untuk 
memberi nama bot, misalnya kita beri nama "KresnaIoT", lalu kita juga diminta menulis username untuk bot tersebut. Setelah menentukan username bot, kita akan diberkan Token dari bot tesebut. Token ini sangat penting dan tidak boleh diketahui orang lain. Token akan berfungsi untuk mengakses HTTP API dari bot tersebut. Dengan kata lain, dengan token tersebut kita dapat mengendalikan bot dan nantinya kode token tersebut akan digunakan pada pemrograman ESP8266. Gambar 10 menunjukkan bahwa bot telah berhasil dibuat.

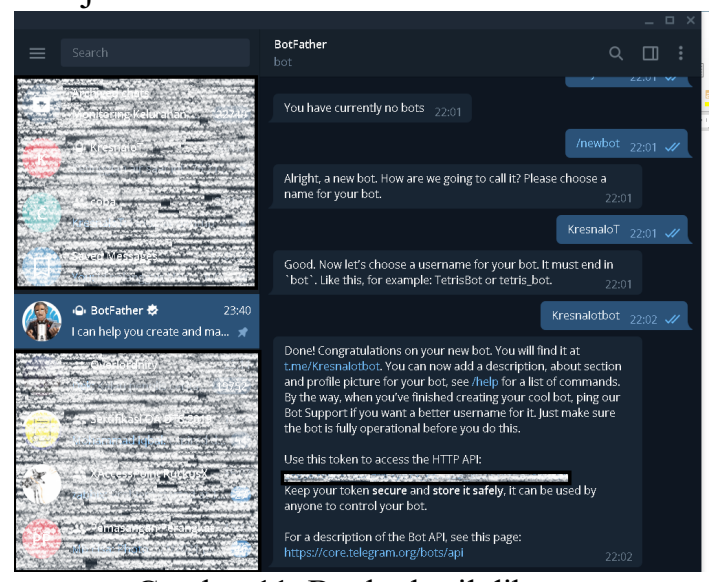

Gambar 11. Bot berhasil dibuat.

IV. HASIL DAN PEMBAHASAN

\section{A. Hasil Perancangan Perangkat Keras}

i Hasil Perancangan Prototype Waduk Hasil dari perancangan prototype ini waduk mempunyai ukuran panjang $34 \mathrm{~cm}$, lebar 29 $\mathrm{cm}$ dan tinggi $11 \mathrm{~cm}$. Terdiri dari Kran otomatis dengan servo, dan sensor Ultrasonik. Berikut adalah gambar dari Prototype waduk.

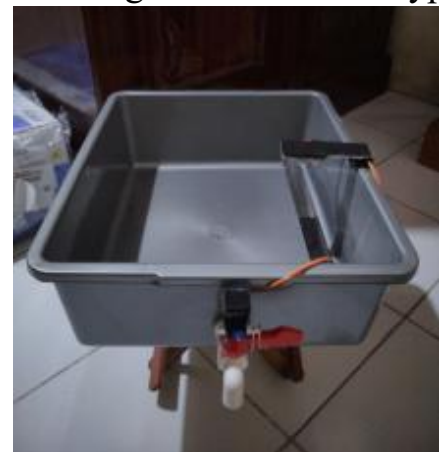

Gambar 12. Prototype Waduk.

ii Hasil Perancangan Elektrik

Perancangan Elektrik terdiri dari rangkaian power supply, rangkaian ESP8266, rangakian sensor ultrasonik.

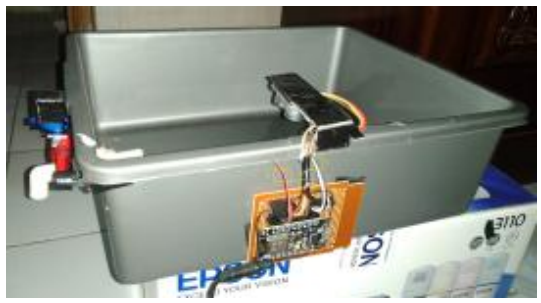

Gambar 13. Rangkaian kontrol menggunakan ESP8266.

\section{B. Hasil Pengujian}

- Pengujian Alat

Alat ini dibuat untuk mendeteksi ketinggain air waduk, kemudian memberitahu dimana batas air berada. Sistem ini akan memberitahu status level air dari $0 \%-100 \%$. Terdapat 3 kondisi, yaitu ketika level 3 tinggi air $80 \%$ $100 \%$ dengan tinggi air $8,8 \mathrm{~cm}-11 \mathrm{~cm}$, ketika level 2 tinggi air 50\% - 70\% dengan tinggi air $5,5 \mathrm{~cm}-7,7 \mathrm{~cm}$, dan ketika level 1 tinggi air $0 \%$ - $30 \%$ dengan tinggi air $0 \mathrm{~cm}-3,3 \mathrm{~cm}$. ESP8266 akan memberikan pesan peringatan ke Telegram ketika tinggi air berada pada level 3 yaitu ketika air hampir penuh atau tinggi air mencapai $80 \%$ - 100\%. Pengguna juga dapat meminta informasi kondisi tinggi air dengan mengetikkan "/air" pada Bot Telegram. Pesan akan dikirim ke ESP8266 kemudian ESP8266 akan meminta informasi tinggi air pada sensor ultrasonik lalu sensor ultrasonik akan memberikan informasi ke ESP8266 dan akan meneruskan informasi ketinggian air tersebut ke Telegram pengguna. Pengujian sistem ini dilakukan uji coba pada Sensor Ultrasonik sebagai pembaca ketinggian air. Tabel 1 menunjukkan pengujian sensor ultrasonik pada waduk sebagai pembaca tinggi air. Data tersebut merupakan perbandingan dari tinggi air yang terbaca oleh sensor dan tinggi air sebenarnya. Dari hasil pengujian didapatkan selisih nilai error yang sedikit antara tinggi air yang terbaca pada sensor dan tinggi air sebenarnya. Tabel 1 merupakan keadaan saat sedang dilakukan kalibrasi pada sensor ultrasonik. 
Tabel 1. Pengujian Sensor Ketinggian

\begin{tabular}{|c|c|c|c|}
\hline No & $\begin{array}{c}\text { Tinggi Air pada } \\
\text { Sensor }(\mathbf{c m})\end{array}$ & $\begin{array}{c}\text { Tinggi } \\
\text { sebenarnya } \\
\text { (cm) }\end{array}$ & $\begin{array}{c}\text { Nilai Error } \\
\mathbf{( \% )}\end{array}$ \\
\hline 1 & 3.1 & 3 & $3.3 \%$ \\
\hline 2 & 6.4 & 6.1 & $4.9 \%$ \\
\hline 3 & 8 & 8 & $0.0 \%$ \\
\hline 4 & 1 & 1 & $0.0 \%$ \\
\hline 5 & 10.3 & 10 & $3.0 \%$ \\
\hline 6 & 9 & 8.7 & $3.4 \%$ \\
\hline 7 & 4.1 & 4 & $2.5 \%$ \\
\hline 8 & 2 & 2 & $0.0 \%$ \\
\hline 9 & 7.3 & 7 & $4.3 \%$ \\
\hline 10 & 5 & 4.9 & $2.0 \%$ \\
\hline & \multicolumn{2}{|c|}{ Rata-rata error } & $2.35 \%$ \\
\hline
\end{tabular}

Error diatas terjadi dikarenakan Sensor Ultrasonik bekerja berdasarkan prinsip rambatan suara pada udara yang kecepatannya bergantung pada temperatur, sehingga perbedaan temperatur bisa jadi menyebabkan error pada sistem.

Dengan motor servo sebagai penggeraknya, Alat ini secara otomatis mengurangi volume air. Kran air bergerak membuka atau menutup sesuai kondisi ketinggian air yang ada pada waduk. Sensor Ultrasonik membaca level air kemudian mengirimkan informasi ke ESP8266 dan ESP8266 akan meneruskan informasi ke motor servo sehingga motor servo dapat bergerak sesuai tinggi air pada waduk. Pada saat tinggi air $0 \%-30 \%$ artinya kondisi waduk cukup kering sehingga kran air akan menutup dan sero bernilai 0 . Sehingga saat ada penambahan air pada waduk, maka tinggi air akan meningkat Saat tinggi air 50\% - 70\%, waduk dalam kondisi normal. Disini kondisi servo akan mengikuti nilai terakhir dari servo, sehingga jika kondisi motor servo menutup maka pada kondisi saat ini motor servo juga akan menutup begitu pula sebaliknya, jika kondisi motor servo terbuka maka pada kondisi saat ini motor servo juga akan terbuka. Dalam kasus jika motor servo terbuka maka volume air yang akan dikeluarkan sebanyak $90.4 \mathrm{~mL} /$ menit. Saat level air kian meningkat sampai $80 \%$ - 100\%, kran akan mengeluarkan volume air sebanyak $144.6 \mathrm{~mL} /$ menit. Tabel 2 menunjukkan data pengujian kran otomatis.

Tabel 2. Data buka tutup kran otomatis

\begin{tabular}{|c|c|c|c|}
\hline No & $\begin{array}{c}\text { Kondisi } \\
\text { Level Air }\end{array}$ & $\begin{array}{c}\text { Posisi Motor } \\
\text { Servo }\end{array}$ & $\begin{array}{c}\text { Volume } \\
\text { Air }\end{array}$ \\
\hline 1 & $\begin{array}{c}\text { Level 3 (80\% } \\
-100 \%)\end{array}$ & Terbuka & $\begin{array}{c}144.6 \\
\mathrm{~mL} / \mathrm{menit}\end{array}$ \\
\hline 2 & $\begin{array}{c}\text { Level 2(50\% } \\
-70 \%)\end{array}$ & Terbuka & $\begin{array}{c}90.4 \\
\mathrm{~mL} / \mathrm{menit}\end{array}$ \\
\hline 3 & $\begin{array}{c}\text { Level 1 }(0 \%- \\
30 \%)\end{array}$ & Tertutup & $0 /$ menit \\
\hline
\end{tabular}

Tabel 3. Penujian buka tutup kran melalui telegram

\begin{tabular}{|c|c|c|c|c|c|c|c|c|}
\hline No & $\begin{array}{c}\text { Terbuka } \\
\text { (detik) }\end{array}$ & $\begin{array}{c}\text { Pesan } \\
\text { Diterima } \\
\text { (detik) }\end{array}$ & $\begin{array}{c}\text { Selisih } \\
\text { (detik) }\end{array}$ & $\begin{array}{c}\text { Eror } \\
\text { (\%) }\end{array}$ & $\begin{array}{c}\text { Tertutup } \\
\text { (detik) }\end{array}$ & $\begin{array}{c}\text { Pesan } \\
\text { Diterima } \\
\text { (detik) }\end{array}$ & $\begin{array}{c}\text { Selisih } \\
\text { (detik) }\end{array}$ & $\begin{array}{c}\text { Eror } \\
(\%)\end{array}$ \\
\hline 1 & 1 & 5 & 4 & 0 & 6 & 9 & 3 & 0 \\
\hline 2 & 8 & 13 & 5 & 0 & 6 & 11 & 5 & 0 \\
\hline 3 & 4 & 8 & 4 & 0 & 7 & 11 & 4 & 0 \\
\hline 4 & 2 & 6 & 4 & 0 & 5 & 8 & 4 & 0 \\
\hline 5 & 4 & 7 & 3 & 0 & 8 & 12 & 4 & 0 \\
\hline 6 & 6 & 11 & 5 & 0 & 6 & 10 & 4 & 0 \\
\hline 7 & 5 & 9 & 4 & 0 & 6 & 11 & 5 & 0 \\
\hline 8 & 4 & 8 & 4 & 0 & 5 & 8 & 3 & 0 \\
\hline 9 & 7 & 12 & 5 & 0 & 7 & 12 & 5 & 0 \\
\hline 10 & 5 & 10 & 5 & 0 & 8 & 13 & 5 & 0 \\
\hline
\end{tabular}

Ketika alat ini bekerja, ESP8266 harus selalu menyala dan terhubung ke jaringan internet. Walaupun ESP8266 sempat terputus dari power, saat menyala lagi alat ini tidak perlu diprogram kembali karena programnya sudah tersimpan dalam ROM dan tidak perlu harus terkoneksi ke PC. ESP8266 terkoneksi ke Telegram pada smartphone melalui internet. Seperti yang sebelumnya sudah dijelaskan, setiap bot memiliki kode token. Token inilah yang nantinya akan mengakses data dari ESP8266 ke server Telegram bot sehingga bot pada Telegram dapat diakses. 


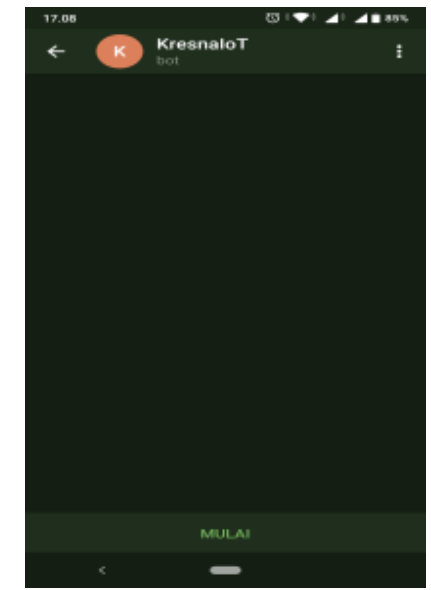

Gambar 14. Tampilan Awal Bot.

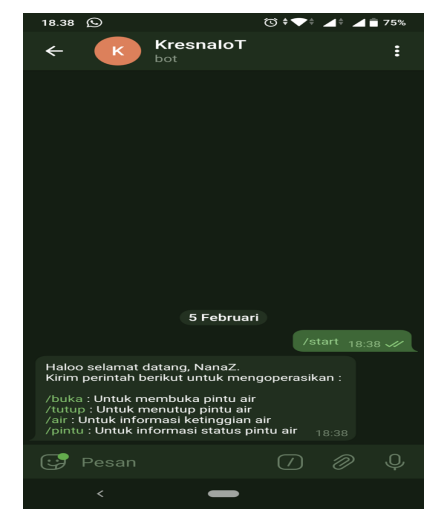

Gambar 15. Tampilan Bot setelah tombol start ditekan.

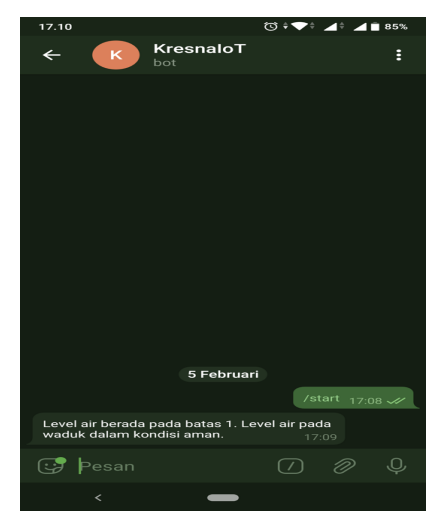

Gambar 16. peringatan kondisi air level 1.

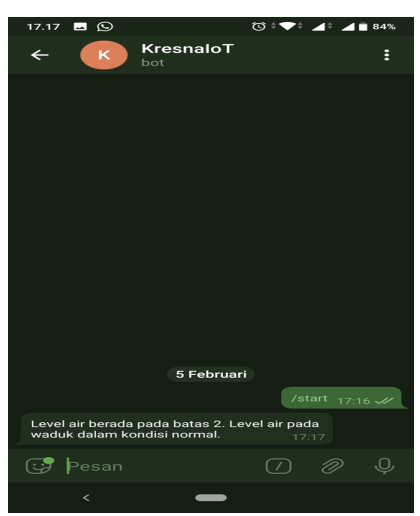

Gambar 17. peringatan kondisi air level 2.

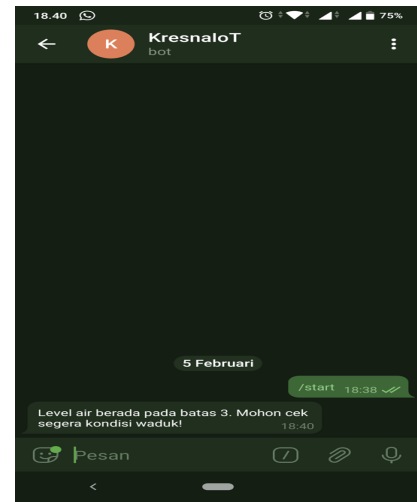

Gambar 18. peringatan kondisi air level 3.

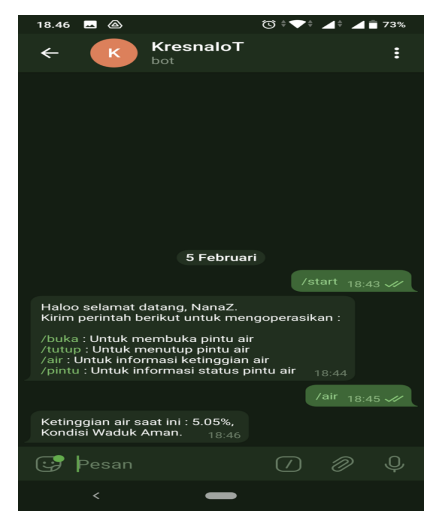

Gambar 19. meminta informasi kondisi air pada sistem.

Seperti yang telah disebutkan sebelumnya, selain pengguna dapat menerima informasi kondisi waduk secara otomatis, pengguna juga dapat meminta informasi mengenai ketinggian air pada waduk dengan cara mengetik /air pada pesan telegram dan / pintu untuk mengetahui kondisi pintu air saat ini.

\section{- Pengujian Alat}

Dari hasil pengujian tersebut, kita dapatkan hasil bahwa sistem berjalan dengan baik, bot telegram dapat mengirim dan menerima pesan, sensor ultrasonik dapat mendeteksi ketinggian dengan error yang kecil, servo dapat membuka dan menutup kran otomatis dengan lancar, dan ESP8266 dapat menerima pesan dan mengeksekusi pesan tersebut.

\section{SIMPULAN}

Didalam pengujian sistem secara keseluruhan, dapat diambil kesimpulan bahwa hasil perancangan dan pembuatan alat prototype waduk berfungsi dengan baik. Eror yang didapatkan dalam ujicoba terjadi dikarenakan 
sensor ultrasonik bekerja berdasarkan prinsip rambatan suara pada udara yang kecepatannya bergantung pada temperatur, sehingga perbedaan temperatur bisa jadi menyebabkan error pada sistem. Secara keseluruhan sistem dapat memberikan informasi tingkat air di waduk.

Pengguna juga bisa meminta informasi level air pada waduk, dimana alat akan memberikan informasi secara otomatis saat air waduk melebih i batas normal.

\section{DAFTAR PUSTAKA}

[1] Budiarso, Z. 2011. SISTEM MONITORING TINGKAT KETINGGIAN AIR BENDUNGAN BEBASIS MIKROKONTROLLER. Jurnal Dinamika Informatika, 3(1).

[2] Tenggono, Alfred. 2015. Sistem Monitoring dan Peringatan Ketinggian Air berbasis Web dan SMS Gateway. Jurnal Ilmiah SISFOTENIKA Vol. 5, No. 2.

[3] Girsang, Irma S. 2013. Perancangan Monitoring Jarak Jauh Ketinggian Air pada Bendungan Menggunakan Sistem Android Via Jaringan Wi-fi. Saintia Fisika, vol. 4, no.1.

[4] Tion, David Karismata W. 2017. Perancangan Bot untuk Remote Monitoring pada Server menggunakan Telegram Bot API. Program Studi Teknik Informatika FTI-UKS

[5] M. Hanif Md Saad, R. Shahad, M. Sarnon, M. Mohd Shukri, \& A. Hussain. 2017. "Smart Pump Operation Monitoring And Notification (PuMa) Via Telegram Social Messaging Application," JOIV : International Journal on Informatics Visualization, vol. 1, no. 3, , pp. 57-60, Jun.

[6] F. Musthofa, and H. Winarno. 2015. "SISTEM DESELERASI KECEPATAN OTOMATIS PADA MOBIL BERDASARKAN JARAK MENGGUNAKAN SENSOR ULTRASONIK HCSR04 BERBASIS ARDUINO MEGA 2560," Gema Teknologi, vol. 18, no. 3, pp. 110-116, Oct.

[7] Puspasari Fitri. 2019. Sensor Ultrasonik HCSR04 Berbasis Arduino Due untuk Sistem Monitoring Ketinggian. JURNAL FISIKA DAN APLIKASINYA VOLUME 15, NOMOR 2, 2019.

[8] Kulkarni, P.V., Joshi, M.S. 2016. An IOT based Water Supply Monitoring and Controlling System with Theft Identification, International Journal of Innovative Research in Science, Engineering and Technology.

[9] Marco, Schwartz. 2015. Home Automation With The ESP8266: Build Home Automation Systems Using the Powerful and Cheap ESP8266 WiFi Chip.

[10] Carullo Alessio and Parvis Marco. 2001. An Ultrasonic Sensor for Distance Measurement in Automotive Applications. IEEE SENSORS JOURNAL, VOL. 1, NO. 2, AUGUST 2001.
[11] Eko Susilo, Kunto. 2019. Increasing Productivity in Agriculture Through Integrated Smart Architecture of Irrigation Systems with LORA Technology. International Journal of Innovation, Creativity and Change. www.ijicc.net Volume 9, Issue 11, 2019

[12] Burange, Anup \& Misalkar, Harshal. (2015). Review of Internet of Things in development of smart cities with data management \& privacy. 189-195. 10.1109/ICACEA.2015.7164693.

[13] L. Yang, Y. Qi, J. Han, C. Wang and Y. Liu, "Shelving Interference and Joint Identification in Large-Scale RFID Systems," in IEEE Transactions on Parallel and Distributed Systems, vol. 26, no. 11, pp. 3149-3159, 1 Nov. 2015, doi: 10.1109/TPDS.2013.276.

[14] "NodeMCU microcontroller board with ESP8266 and Lua ". Accessed on: Nov. 3, 2020.[Online].Available:https://www.elektor.com/nod emcu-microcontroller-board-with-esp8266-and-lua

[15] Eko Susilo, Kunto. 2019. INTERNET OF THINGS (IoT) BASED TEXTBOOK CHECKER TOOL. SEMINAR SANTIKA 4-5 SEPTEMBER 2019.

[16] Eko Susilo, Kunto. 2019. Learning Smart through REKBEN Tube for Basic Electric and Electronic Subjects . International Journal of Innovation, Creativity and Change. www.ijicc.net Volume 9, Issue 11,2019 